\title{
Inclusão de alunos com deficiência nos colégios de aplicação: a perspectiva de seus diretores
}

Régis Henrique dos Reis Silva* Thiago Vaz Santiago**

\section{Resumo}

Este estudo tem como tema central a matrícula de alunos com deficiência nos Colégios de Aplicação das Instituições Federais de Ensino Superior (CAP/IFES). Seu objetivo geral é analisar a situação vivenciada pelos alunos com deficiência nos CAP/IFES, na perspectiva dos seus diretores, diante das políticas nacionais de Educação Especial. Esta pesquisa caracteriza-se como um estudo de campo de caráter analítico-crítico e está delimitada a quinze CAP/IFES. A população do estudo foi composta pelos diretores dos CAP/IFES que exerciam esta função no primeiro semestre de 2008. Foram encaminhados questionários (semiestruturados) para todos os diretores dos colégios supramencionados, dos quais, dez $(66,7 \%)$ foram efetivamente respondidos. Para análise dos questionários, verificou-se o percentual e o conteúdo das respostas apresentadas pelos diretores. Os dados obtidos apontam com exatidão o número de alunos com deficiência matriculados nos CAP/IFES e a realidade situacional desses alunos, segundo a visão dos diretores dessas instituições. Os diretores também relataram suas concepções de inclusão escolar e as principais dificuldades vivenciadas pelas instituições que dirigem diante do desafio apresentado pelas políticas nacionais de Educação Especial. Dentre essas dificuldades destaca-se a falta de formação dos educadores, o que compromete a compreensão e a análise crítica do ideário inclusivista, dificultando a superação de práticas retrógradas (explícitas ou implícitas) que aumentam a exclusão educacional e social dos alunos com deficiência e das novas gerações.

Palavras-chave: Educação Especial. Inclusão Escolar. Colégios de Aplicação.

\section{Inclusion of students with disabilities in schools of application: perspective of its directors}

\section{Abstract}

This study has as its central theme the enrollment of students with disabilities in Colleges Application of Federal Institutions of Higher Education (CAP/IFES). Its general purpose is to analyze the situation experienced by students with disabilities in the CAP/IFES in view of its directors on national policies for Special Education. This research is characterized as a field study of analytical-critical and is bounded to fifteen CAP/IFES. The study population was composed of directors of CAP/IFES, who performed this function in the first half of 2008 . Were

\footnotetext{
* Professor Assistente da Universidade Federal de Goiás e doutorando em Filosofia e História da Educação pela Unicamp. Campinas, São Paulo, Brasil.

** Professor da Rede Estadual de Ensino de Goiás (REE/GO), Goiânia, Goiás, Brasil.
} 
sent questionnaires (semistructured) for all principals of the schools mentioned above, of which ten (66.7\%) were actually answered. For analysis of the questionnaires it was found and the percentage content of the replies submitted by the directors. The data indicate the precise number of disabled students enrolled in the CAP/IFES and the situational reality of these students, according to the vision of the directors of these institutions. The directors also reported their conceptions of school enrollment and the main difficulties experienced by institutions that drive before the challenge presented by national policies of Special Education. Among these difficulties we highlight the lack of training for educators, which hinders the understanding and critical analysis of ideas inclusivist, making it difficult to overcome retrograde practices (explicit or implicit) that increase the educational and social exclusion of disabled students and new generations.

Keywords: Special Education. School Inclusion. Schools Application.

\section{Introdução}

Este estudo tem como tema central a matrícula de alunos com deficiência ${ }^{1}$ nos Colégios de Aplicação das Instituições Federais de Ensino Superior (CAP/IFES). Seu objetivo geral é analisar a situação vivenciada pelos alunos com deficiência nos CAP/IFES, na perspectiva dos seus diretores, diante das políticas nacionais de Educação Especial (EEs). ${ }^{2}$

No Brasil, especialmente a partir dos anos 1980, observa-se um incremento na produção científica voltada para o tema da deficiência. Segundo Carmo (1991), isso se justifica pela preocupação que, mundialmente, passou a existir para com as pessoas deficientes, a partir de 1981, que foi considerado o "Ano Internacional para as Pessoas Deficientes".

Entretanto, o direito da pessoa com deficiência à Educação já é objeto do aparato jurídico educacional brasileiro desde a "[...] Lei de Diretrizes e Bases da Educação Nacional (LDBEN), Lei no 4.024/61, que aponta o direito dos 'excepcionais' à educação, preferencialmente dentro do sistema geral de ensino" (BRASIL, 2008, p. 2). Efetivamente, as formulações de políticas de EEs no Brasil só ocorreram a partir dos anos 1990, pois, antes desse período, estas se caracterizavam por campanhas assistenciais e iniciativas isoladas do Estado.

Nesse sentido, a primeira política nacional de destaque, intitulada de "Política Nacional de Educação Especial", foi promulgada em 1994. Posteriormente, em 2003, o Ministério da Educação (MEC) iniciou a implementação do Programa Educação Inclusiva: direito à diversidade, cujo objetivo era

[...] apoiar a transformação dos sistemas de ensino em sistemas educacionais inclusivos, promovendo um amplo processo de formação de gestores e educadores 
nos municípios brasileiros para a garantia do direito de acesso de todos à escolarização, à oferta do atendimento educacional especializado e à garantia da acessibilidade. (BRASIL, 2008, p. 4)

E, mais recentemente, em janeiro de 2008, o governo brasileiro promulgou a Política Nacional de Educação Especial na perspectiva da Educação Inclusiva, apresentando esta como um movimento mundial que age pela via política, cultural, social e pedagógica, e que fora desencadeada em defesa do direito de todos os alunos de estarem juntos, aprendendo e participando, sem nenhum tipo de discriminação (BRASIL, 2008).

De acordo com essa política,

[...] a Educação Inclusiva constitui um paradigma educacional fundamentado na concepção de direitos humanos, que conjuga igualdade e diferença como valores indissociáveis, e que avança em relação à ideia de equidade formal ao contextualizar as circunstâncias históricas da produção da exclusão dentro e fora da escola. (BRASIL, 2008, p. 1)

A partir do estudo de Silva, Sousa e Vidal (2008), observamos que aumentaram os indicadores da Educação Especial no Brasil, no período de 1996 a 2006. Nas redes municipais, por exemplo, o aumento no número das matrículas do seu alunado foi de 235.462 (aproximadamente $800 \%$ ), nas redes estaduais de 84.297 (aproximadamente 100\%), nas redes privadas de 179.544 (mais de 230\%), nas escolas da rede federal de ensino o aumento foi de apenas 179 (aproximadamente 20\%) e, na soma geral, foi de 499.482 (aproximadamente $250 \%)$.

Desses dados, podemos inferir que há um aumento significativo na matrícula do alunado da EEs nas escolas básicas brasileiras das redes públicas (municipais e estaduais) e privadas (geralmente filantrópicas), mas o mesmo não ocorre com a rede pública federal.

Nesse sentido, realizamos um levantamento bibliográfico no intuito de identificar os estudos da área educacional que, nos últimos anos, discutiram esta temática e verificamos que são escassos os trabalhos voltados para análises situacionais dos alunos com deficiência nos CAP/IFES.

Assim, desenvolvemos este estudo, a fim de responder à seguinte questão central: Qual a situação vivenciada pelos alunos com deficiência nos CAP/IFES, na perspectiva dos seus diretores, diante das políticas nacionais de EEs?Os diretores dos CAP/IFES são professores eleitos entre em seus pares para exercerem o cargo de direção. Os professores dos CAP/IFES são servidores públicos federais, geralmente concursados pelo Regime Jurídico Único, lotados nos CAP das IFES, onde a maioria trabalha sob o regime de quarenta 
horas de trabalho semanal com dedicação exclusiva. Esses professores são doutores, mestres e pesquisadores envolvidos com o ensino nos níveis infantil, fundamental, médio e superior, e têm como funções o ensino, o desenvolvimento da pesquisa, a experimentação de novas práticas pedagógicas, a formação de professores, a criação, implementação e avaliação de novos currículos e capacitação de docentes (CEPAE/UFG, 2009).

Portanto, podemos inferir que os CAP/IFES apresentam um potencial inovador importante na formulação de novas práticas pedagógicas, novos currículos, entre outras novidades acerca da Organização do Trabalho Pedagógico (OTP) que, em um contexto de transformação dos sistemas de ensino em sistemas educacionais inclusivos, como preconiza o Programa Educação Inclusiva: direito à diversidade do MEC e a Política Nacional de EEs na perspectiva da Educação Inclusiva, poderia estar sendo mais bem explorado.

Mas o que se verifica não é isso, pelo menos nos números da matrícula do alunado da EEs na rede pública federal. Por esse motivo, vemos a necessidade de uma análise situacional dos alunos com deficiência na perspectiva dos dirigentes dos CAP/IFES. Ainda consideramos que a falta de informações sistematizadas sobre essa questão seja um elemento complicador não só na superação dos inúmeros problemas enfrentados pelas pessoas com deficiência, mas também no avanço acadêmico-científico da área educacional brasileira.

\section{Procedimentos metodológicos}

Esta pesquisa caracteriza-se como um estudo de campo de caráter analítico-crítico e está delimitada a quinze CAP/IFES, ${ }^{3}$ listados no quadro 1 , no qual descrevemos o nome de cada colégio e a respectiva IFES ao qual se vincula. ${ }^{4}$ 


\begin{tabular}{|l|l|}
\hline Nomes dos Colégios & IFES \\
\hline 1. Colégio de Aplicação - CAP & UFRGS \\
\hline 2. Colégio de Aplicação - CAP & UFSC \\
\hline 3. Colégio de Aplicação "João XXIII" & UFJF \\
\hline 4. Escola de Educação Básica - ESEBA & UFU \\
\hline 5. Escola Fundamental do Centro Pedagógico & UFMG \\
\hline $\begin{array}{l}\text { 6. Centro de Ensino e Pesquisa Aplicada à Educação - } \\
\text { CEPAE }\end{array}$ & UFG \\
\hline 7. Colégio de Aplicação - CAP & UFAC \\
\hline 8. Colégio de Aplicação - CAP & UFRR \\
\hline 9. Núcleo de Educação Infantil - NEI & UFRN \\
\hline 10. Colégio de Aplicação - CAP & UFRJ \\
\hline 11. Colégio Universitário - COLUN & UFMA \\
\hline 12. Colégio de Aplicação - CAP & UFPE \\
\hline 13. Colégio de Aplicação - CODAP & UFS \\
\hline 14. Colégio de Aplicação - COLUNI & UFV \\
\hline 15. Núcleo Pedagógico Integrado - NPI & UFPA \\
\hline
\end{tabular}

Quadro 1 - Nome dos Colégios de Aplicação e das IFES às quais se vinculam.

Foram encaminhados questionários (semiestruturados) para todos os diretores das escolas supramencionadas, que exerciam esta função no primeiro semestre de 2008 , dos quais dez $(66,7 \%)$ foram efetivamente respondidos.

No quadro 02, podemos visualizar os CAP/IFES aos quais estão vinculados os dez diretores que responderam os questionários enviados. 


\begin{tabular}{|l|}
\hline Nomes dos Colégios \\
\hline 1. CAP- UFRGS \\
\hline 2. CAP- UFSC \\
\hline 3. CAP- UFJF \\
\hline 4. CEPAE-UFG \\
\hline 5. CAP- UFAC \\
\hline 6. CAP- UFRR \\
\hline 7. CAP- UFRJ \\
\hline 8. COLUN- UFMA \\
\hline 9. CAP-UFMA \\
\hline 10. CAP- UFV \\
\hline
\end{tabular}

Quadro 2 - Demonstrativo dos colégios os quais estão vinculados os diretores participantes da pesquisa.

As perguntas dos questionários foram construídas objetivando fornecer um diagnóstico da situação vivenciada pelos alunos com deficiência nos CAP/IFES diante das políticas nacionais de EEs.

Para realizarmos a análise dos questionários, verificamos o percentual e o conteúdo das respostas apresentadas pelos diretores.

\section{Resultados}

Nos questionários encaminhados aos diretores, perguntamos qual o conceito de inclusão escolar, com o intuito de analisar como eles compreendem as políticas nacionais de EEs, principalmente o "Programa Educação Inclusiva: direito à diversidade" e a "Política Nacional de EEs na perspectiva da Educação Inclusiva", que se fundamentam no ideário inclusivista.

No quadro 03, apresentamos, de forma resumida, as respostas obtidas nos questionários. 


\begin{tabular}{|l|l|l|}
\hline Conceitos & $\mathrm{N}^{\mathbf{0}=10}$ & $\%$ \\
\hline $\begin{array}{l}\text { A- Definem como garantia de direito ao acesso, permanência e } \\
\text { qualidade do ensino oferecido a todos os alunos } \\
\text { indistintamente, respeitando a diversidade humana }\end{array}$ & 4 & 40 \\
\hline $\begin{array}{l}\text { B- Definem como inserção de todos os alunos nos ambientes } \\
\text { escolares e sociais }\end{array}$ & 3 & 30 \\
\hline $\begin{array}{l}\text { C- Não conceituam, mas reconhecem a importância e } \\
\text { consideram de difícil implantação }\end{array}$ & 2 & 20 \\
\hline E- Desconhece a proposta & 1 & 10 \\
\hline
\end{tabular}

Quadro 3 - Demonstrativo do número e percentual dos conceitos de inclusão escolar fornecidos pelos diretores dos CAP/IFES.

Como podemos observar no quadro 3 , quatro diretores (40\%) aproximaram-se de um conceito de inclusão escolar tal como preconizado pelas políticas nacionais de EEs. Esses diretores fizeram alusão ao direito de acesso, permanência e qualidade de ensino oferecido a todos os alunos indistintamente, bem como ao respeito à diversidade humana. ${ }^{5}$

Como um processo de acesso e permanência de alunos [...] socialmente excluídos (D. 2).

$O$ ato de propiciar condições para que todos possam ter acesso, permanecer e ter sucesso na escola (D. 5).

Convívio com a diversidade, em respeito às diferenças (D. 9).

Entendemos que a garantia do direito ao acesso, a qualidade do ensino e a permanência na escola de todos os alunos indistintamente, tal como defendido por esses diretores, geralmente tem sido também os principais aspectos levantados pelos defensores do ideário inclusivista. No entanto, temos defendido que tal princípio só se sustenta com mudanças estruturais na organização escolar (seus tempos, espaços, normas e relações, além da forma do trato do conhecimento, a partir de outras bases epistemológicas, ontológicas e axiológicas) e na organização social mais ampla, pois nestas estão a base para que as mudanças de atitudes e de concepções dos Homens se concretizem, passando de utopia para realidade.

Nas nossas análises, pudemos observar que três diretores (30\%) entendem a inclusão escolar como um processo de inserção dos alunos excluídos nos ambientes escolares e sociais.

A inclusão escolar deve ser compreendida dentro de
um processo que poderíamos denominar de
acessibilidade, ou seja, práticas pedagógicas e sociais
orientadas no sentido de inserção do discente às 


\begin{abstract}
diversas atividades escolares. Dentre essas, destacaríamos acesso físico aos locais frequentados por todos, além da tão comentada inclusão digital, por meio de laboratórios eletrônicos (D. 4).

Um processo que permite a inserção de todos os indivíduos nos diferentes ambientes sociais, em igualdade de avaliação, direitos, reconhecimento etc. (D. 8).
\end{abstract}

A partir das respostas fornecidas pelos diretores identificados como D. 4 e D. 8, podemos afirmar que eles desconhecem que o princípio da inclusão escolar vai além da simples "inserção" dos "excluídos" aos ambientes escolares e sociais, pois a "inserção" por si só não garante a qualidade do ensino e a permanência dos alunos na instituição escolar, assim como a participação plena na sociedade.

Encontramos dois diretores (20\%) que não apresentaram nenhum conceito de inclusão escolar, mas reconheceram a sua importância e consideraram-na de difícil implantação:

Um projeto muito bem intencionado, porém de difícil aplicabilidade (D. 6).

Como uma necessidade, mas algo que não é simples e nem é fácil de ser implantado (D. 10).

Entendemos que a inclusão escolar vai além de um projeto bem intencionado, como nos colocou D. 6, pois, como já afirmarmos, o princípio inclusivista só se sustenta com mudanças estruturais na organização escolar e na organização social mais ampla.

Nesse sentido, concordamos com D. 10 quando ele afirma que é uma questão de necessidade, até porque, historicamente, vários alunos foram excluídos do sistema escolar, seja por falta de acesso seja por evasão, o que trouxe sérios comprometimentos para formação da personalidade e participação social desses alunos (CARMO, 2006).

Com relação às afirmações de D. 6 e D.10 quanto ao fato de a inclusão escolar ser de difícil aplicabilidade ou implantação, gostaríamos de observar que, para o Homem, o possível e o impossível são relativos, haja vista os avanços recentes da Ciência e da Tecnologia e os feitos realizados pelo conhecimento científico e tecnológico. Em face disso,não podemos nos esquecer que muitas das dificuldades enfrentadas na solução dos problemas humanos mudam conforme os interesses em solucioná-los, assim como a forma dos envolvidos em tentar resolvê-los, em outras palavras, problemas histórico-sociais são resolvidos histórica e coletivamente.

Assim como Kassar (1998), avaliamos que as políticas públicas no Brasil, mais especificamente aquelas promotoras de distribuição de renda e 
garantidoras de direitos sociais básicos, são oriundas de formulações políticas antagônicas, em que prevalecem as estratégias de conciliação em sua constituição, pois, na cultura política brasileira, geralmente, as reivindicações históricas da população trabalhadora e das pessoas com deficiência são, em alguns casos, incorporadas às leis, mas não se concretizam efetivamente na realidade social, pois a atuação do Estado no sentido de garantir as condições necessárias para que as mudanças estruturais aconteçam não são dadas e/ou viabilizadas e, consequentemente, não se realizam.

Por fim, apenas um diretor (10\%) desconhece a proposta de inclusão escolar, visto que respondeu: "não sei" (D. 3). Esta resposta, embora em menor número que as demais, nos preocupa, pois explicita um profundo descompasso entre o que está ocorrendo na realidade das escolas dos municípios e dos estados brasileiros e o que pode estar ocorrendo ou não na instituição da qual este diretor é o seu dirigente máximo, com o agravante daquela ser um colégio vinculado a uma IFES, que, entre outras funções, como já foi dito anteriormente, também atua na formação inicial de professores e conta, no seu quadro docente, com mestres e doutores.

Enfim, esta resposta abre a possibilidade para diferentes interpretações, mas a que mais nos chamou a atenção é o paradoxo da realidade escolar dos municípios e dos estados brasileiros, ocasionado por uma política normativa, massificada e generalizada pelo MEC para todo País, quando instituições de educação básica vinculadas a este mesmo Ministério, pelo menos um dos seus dirigentes, sequer conhecem a política do órgão ao qual se subordinam.

No quadro 4, podemos visualizar os colégios administrados pelos dez diretores respondentes, número e tipos de deficiência existentes em cada instituição. 


\begin{tabular}{|l|c|c|c|c|c|c|c|}
\hline & \multirow{2}{*}{ Nomes dos Colégios } & No de alunos \\
& com deficiência & \multicolumn{5}{|c|}{ Tipos de Deficiência } \\
\cline { 5 - 9 } & & DM & DA & DV & DF & DMU & OUTROS \\
\hline 1. CAP- UFRGS & 1 & & & & $X$ & & \\
\hline 2. CAP- UFSC & 21 & & & $X$ & $X$ & $X$ & $X$ \\
\hline 3. CAP- UFJF & 1 & $X$ & & & & & \\
\hline 4. CEPAE-UFG & 3 & $X$ & & & & & $X$ \\
\hline 5. CAP- UFAC & 4 & & & & & & $X$ \\
\hline 6. CAP- UFRR & 0 & & & & & & \\
\hline 7. CAP- UFRJ & 1 & & & & $X$ & & \\
\hline 8. COLUN- UFMA & 6 & & & $X$ & $X$ & & \\
\hline 9. CAP-UFMA & 6 & & $X$ & & $X$ & & $X$ \\
\hline 10. CAP- UFV & 1 & & & $X$ & & & \\
\hline Total & 44 & & & & & \\
\hline
\end{tabular}

Quadro 4 - Demonstrativo dos colégios administrados pelos dez diretores que participaram da pesquisa, o número de alunos com deficiência e os tipos de deficiência existentes em cada escola vinculadas às IFES.

O quadro 4 demonstra os resultados do levantamento realizado junto aos dez diretores dos CAP/IFES sobre o número e os tipos de deficiências dos alunos com deficiência matriculados nas instituições em que dirigem. Nesse sentido, destacamos:

1. Existe nos colégios por eles administrados um total de 44 alunos com deficiência matriculados na educação básica;

2. Os tipos de deficiência dos alunos matriculados nos colégios são: deficiência auditiva (DA), visual (DV), mental (DM), física (DF), múltipla (DMU) e outros; ${ }^{6}$

3. O tipo de deficiência mais frequente nos colégios é a física, aparecendo em cinco das dez instituições;

4. A deficiência auditiva (DA) foi o tipo de deficiência menos frequente nos colégios, sendo apontada apenas no CAP da UFPE;

5. O colégio que possui o maior número de alunos com deficiência matriculados na educação básica é o CAP da UFSC, com 21 alunos; 
6. E o CAP da UFRR não apresenta nenhum aluno com deficiência matriculado.

Esses dados confirmam o que fora verificado por Silva, Sousa e Vidal (2008) acerca dos baixos índices de alunos das EEs e, mais precisamente, de alunos com deficiência matriculados na rede pública federal de ensino, bem como o fato de que o potencial inovador dos CAP/IFES na formulação de novas práticas pedagógicas, novos currículos e outras novidades referentes à OTP é pouco explorado no contexto das políticas de EEs no Brasil.

Assim sendo, buscamos saber dos diretores dos CAP/IFES quais eram as principais dificuldades encontradas pela sua instituição para garantir o acesso, a permanência e o sucesso escolar dos alunos com deficiência, caso elas existissem. $O$ quadro 5 demonstra as dificuldades elencadas pelos diretores e o número de incidência de cada resposta.

\begin{tabular}{|l|l|l|}
\hline Dificuldades & $\begin{array}{l}\mathbf{N}^{\circ} \text { de } \\
\text { incidên- } \\
\text { cia }\end{array}$ & $\%$ \\
\hline $\begin{array}{l}\text { A- Falta de acompanhamento e apoio de profissionais } \\
\text { especializados }\end{array}$ & 5 & 33,3 \\
\hline B- Acessibilidade ao espaço físico & 4 & 26,7 \\
\hline C- Falta de preparação e formação dos professores & 3 & 20,0 \\
\hline D- Nenhuma dificuldade & 2 & 13,3 \\
\hline E- Falta de equipamentos para trabalhar com esse alunado & 1 & 6,7 \\
\hline TOTAL & 15 & 100 \\
\hline
\end{tabular}

Quadro 5 - Demonstrativo das principais dificuldades que os CAP/IFES vêm enfrentando para a inclusão das PD na educação básica, segundo os seus diretores, por número de incidência de cada resposta.

O quadro 5 revela que, segundo os diretores dos CAP/IFES, a falta de apoio de profissionais especializados aparece como sendo a principal dificuldade enfrentada pelas referidas instituições, com $33,3 \%$ das respostas.

Acreditamos que essas respostas remetem ao "estranhamento" e ao desconhecimento dos profissionais da educação em trabalhar com os alunos com deficiência junto com os demais, o que, em primeiro momento, diante da diferença, levam-nos a recorrer aos profissionais que, historicamente, trabalharam com as Pessoas com Deficiência. Segundo Lopes e Tunes (2006), esse "estranhamento" perante a diversidade existente entre os alunos ocorre porque, historicamente, a escola postulou e ainda postula um tipo ideal de aluno.

A acessibilidade dos alunos com deficiência $(26,7 \%)$ e a falta de equipamentos para se trabalhar com eles $(6,7 \%)$ somam $33,4 \%$ das respostas dos 
diretores dos CAP/IFES. Entendemos que os diretores que afirmam serem estas as principais dificuldades para implantação e construção de uma instituição "inclusiva" se equivocam ao acreditarem que apenas reformando as estruturas físicas dos colégios e dispondo de materiais didádico-pedagógicos adaptados garantirão o sucesso escolar da PD.

De acordo com Carmo (2001), podemos denominá-los como "reformistas", pois acreditam que a desigualdade existente entre os alunos desaparecerá no momento em que a escola regular prover a equidade de oportunidades para todos.

Porém, se a inclusão não for feita com mudanças concretas na organização escolar, esta instituição continuará camuflando as desigualdades e as diferenças existentes entre os alunos, e o pior, concretizando o fenômeno que Freitas (2002) intitula de internalização da exclusão, que consiste em transferir para o aluno a responsabilidade pelo seu fracasso ou sucesso escolar, pois se argumenta que as oportunidades educacionais ofertadas são iguais, o acesso e a "permanência" foram viabilizados, a acessibilidade e os recursos necessários garantidos, ignorando que a exclusão educacional tem uma dimensão objetivosocial, geralmente, mais determinante que a dimensão subjetiva dos indivíduos.

A formação docente indicada em $20 \%$ das respostas dos diretores é um fator crucial para nós, pois pode ser o início de um processo de reflexão e revisão de práticas excludentes na escola, ao mesmo tempo em que se articulam as discussões mais amplas acerca dos objetivos da educação (formal e informal), na Cultura geral da sociedade e de suas possibilidades emancipadoras, na construção de uma educação para além do capital, conforme sugere Mészáros (2005).

Por fim, 13,3\% dos diretores afirmaram não enfrentar nenhuma dificuldade. Se a discussão sobre a matrícula dos alunos com deficiência na escola básica brasileira fosse uma questão superada, já resolvida pelo nosso sistema educacional, essas respostas não mereceriam grandes destaques, mas, infelizmente, essas respostas fogem à regra, pelo menos naquilo que tem sido relatado pelos professores, pesquisadores e dirigentes educacionais no Brasil, quando questionados sobre os desafios decorrentes das políticas nacionais de EEs.

Assim sendo, entendemos que essas respostas explicitam, em linhas gerais, o que foi constatado por nós neste estudo e também por Silva, Sousa e Vidal (2006), qual seja: o número de alunos com deficiência matriculados nos CAP/IFES ainda são insignificantes diante da demanda, o que permite a estas instituições enfrentarem, pelo menos aparentemente, as necessidades desse alunado com pequenas adaptações em sua organização escolar. 


\section{Considerações finais}

Entendemos que esta pesquisa de campo oportunizou-nos verificar com exatidão o número de alunos com deficiência matriculados nos CAP/IFES e a realidade situacional dessas pessoas na visão dos diretores dessas instituições.

Nesse sentido, os diretores relataram suas concepções de inclusão escolar e as dificuldades vivenciadas pelas instituições que dirigem diante do desafio apresentado pelas políticas nacionais de Educação Especial. Dentre essas dificuldades, destacamos a falta de formação dos educadores acerca do tema em questão, o que compromete a compreensão e a análise crítica do ideário inclusivista.

O comprometimento da compreensão acontece, porque, muitas vezes, os educadores limitam o paradigma inclusivo a adaptações arquitetônicas e dos conteúdos escolares, valorizando, em alguns casos, a socialização dos alunos com deficiência em detrimento da apreensão por parte destes do conhecimento historicamente produzido pelo Homem e veiculado pela escola. Embora reconheçamos nos limites do modo de produção capitalista um avanço, o fato de haver pessoas com deficiência matriculadas nos CAP/IFES, assim como o é na Educação Inclusiva, visto que há pouco menos de três décadas essas pessoas sequer eram aceitas nas escolas regulares. Isso demonstra, portanto, tratar-se de um movimento contraditório.

Quanto ao comprometimento da criticidade, embora o paradigma inclusivo levante questões acerca das "diferenças" e possibilite o acesso da pessoa com deficiência à escola regular, trata-se uma política que se articula a um conjunto de prescrições neoliberais ${ }^{7}$ e ao modelo político de Estado Mínimo nas políticas sociais e máximo para as políticas econômicas. Portanto, trata-se, segundo Sanfelice (2006), de uma política compensatória dentre outras avaliadas por indicadores quantitativos mais do que qualitativos.

Assim sendo, se este movimento não possibilitar aos educadores e à sociedade em geral ir "à raiz" dos problemas sociais e educacionais, possibilitando a compreensão histórica das diferenças e dos mecanismos explícitos e implícitos de exclusão educacional e social, como elementos justificadores das desigualdades sociais, em especial, da acumulação privada dos meios de produção e a exploração do homem pelo homem, seus resultados poderão ser o acirramento dos estigmas e preconceitos para com as pessoas com deficiência. Isto porque ao mesmo tempo em que os governos brasileiros (Federal, Estadual e Municipal) implementam uma política nacional fundamentada no princípio da diferença e no respeito ao tempo de aprendizagem de cada aluno, também implementam uma política de "avaliação" educacional atrelada ao financiamento escolar e à complementação salarial dos docentes, ${ }^{8}$ que padroniza as avaliações e as expectativas de resultados dos alunos, gerando entre as escolas e os professores uma lógica competitiva pouco salutar para a área edu- 
cacional e a sociedade em geral, hodiernamente tão carente de práticas de solidariedade, cooperação entre outros valores axiológicos do mesmo sentido.

Por tudo isso, afirmamos a necessidade de uma mudança radical na organicidade da escola (seus tempos, espaços, relações de poder, trato com conhecimento), ao mesmo tempo em que se constitua uma educação geral, com uma nova visão de mundo, homem e sociedade, amparada em mudanças estruturais da organização social mais ampla, para que, dessa forma, aumentem as oportunidades de acesso, permanência e sucesso educacional e social de todas as pessoas, inclusive as pessoas com deficiência.

Apesar das limitações deste trabalho, esperamos que ele contribua para a área de EEs, no sentido de suscitar reflexões acerca do trabalho pedagógico presente nos CAP/IFES, no intuito de estes virem a materializar práticas inclusivas em suas intervenções, assim como seja mais bem aproveitado pelo MEC o potencial inovador dessas instituições nos momentos de formulação de políticas educacionais de Educação Básica e formação de professores, antes de serem massificadas e generalizadas para todas as escolas do País.

Salientamos a necessidade de que sejam realizadas mais pesquisas sobre o assunto, no sentido de investigar qual a situação vivenciada pelos alunos com deficiência nas diversas escolas do Brasil e nas diversas áreas do conhecimento, para que, conforme sugere Sanfelice (2006), com base em determinações subjetivas, consigamos coletivamente programar ações objetivas que superem práticas retrógradas (explícitas ou implícitas) que conservam e/ou aumentam a exclusão educacional e social das novas gerações.

\section{Referências}

BRASIL. Ministério da Educação. Secretaria de Educação Especial. Política Nacional de Educação Especial na Perspectiva da Educação Inclusiva. Brasília: MEC/SEESP, 2008.

CARMO, A. A. do. Deficiência física: A sociedade brasileira cria, "recupera" e discrimina. 2. ed. Brasília: Secretaria dos Desportos/PR, 1991. 230 p.

. Inclusão escolar: roupa nova em corpo velho. Revista Integração, Brasília, n. 23, p. 43-47, 2001.

A escola não seriada e inclusão escolar: a pedagogia da unidade na diversidade. Uberlândia: EdUFU, 2006. 132 p.

CEPAE. Centro de Ensino e Pesquisa Aplicada a Educação. Trajetória e funções. Goiânia: CEPAE/UFG, 2009. Disponível em: <http://www.cepae.ufg.br>. Acesso em: 13 fev. 2009.

ESEBA. Escola de Educação Básica. Lista de outras escolas de $1^{\circ}$ e $2^{\circ}$ graus dentro da rede pública federal. Uberlânida: ESEBA/UFU, 2007. Disponível em: <http://www.eseba.ufu.br/cap.php>. Acesso em: 18 maio 2007. 
FREITAS, L. C. de. A internalização da exclusão. Educação e Sociedade, Campinas, v. 23, n. 80, p. 299-325, set. 2002.

KASSAR, M. de C. M. Liberalismo, neoliberalismo e educação especial: algumas implicações. Cadernos CEDES, Campinas, v.19, n. 46, p.16-28, set. 1998.

LOPES, N. A.; TUNES, E. Deficiência e inclusão escolar: o significado da escola. In: ENCONTRO DE PESQUISA EM EDUCAÇÃO DA REGIÃO CENTROOESTE DAASSOCIAÇÃO REGIONAL DE PÓS-GRADUAÇÃO E PESQUISA EM EDUCAÇÃO - Epeco/Anped, 8., 2006, Cuiabá. Anais eletrônicos... Cuiabá, 2006.

MÉSZÁROS, I. A educação para além do capital. São Paulo: Boitempo. 2005.

SANFELICE, J. L. Inclusão educacional no Brasil: limites e possibilidades. Revista de Educação/PUC-Campinas, Campinas, n.21, p. 29-40. nov. 2006.

SILVA, R. H. dos R.; SOUSA, S. B.; VIDAL, M. H. C. Dilemas e perspectiva da Educação Física diante do paradigma da inclusão. Revista Pensar a Prática, Goiânia, v.11, n.2, p. 125-135. maio/ago. 2008.

VIDAL, M. H. C. V. Atando nós que constroem redes... A expansão da rede Pitágoras no contexto da transnacionalização da educação. 2006. 159 f. Dissertação (Mestrado em Educação)-Universidade Federal de Uberlândia, Uberlândia, 2006.

\footnotetext{
Notas

${ }^{1} \mathrm{O}$ termo deficiência será utilizado, neste estudo, para se referir à pessoa que tem impedimentos de longo prazo, de natureza física, mental ou sensorial que, em interação com diversas barreiras, podem ter restringida sua participação plena e efetiva na escola e na sociedade (BRASIL, 2008, p. 9).

${ }^{2}$ A educação especial é uma modalidade de ensino que perpassa todos os níveis, etapas e modalidades. $\mathrm{E}$, integrada à proposta pedagógica da escola regular, realiza o atendimento educacional especializado a alunos com necessidades educacionais especiais (alunos com deficiência, transtornos globais de desenvolvimento e altas habilidades/superdotação), além de orientar a organização de redes de apoio, a formação continuada, a identificação de recursos, serviços e o desenvolvimento de práticas colaborativas (BRASIL, 2008).

${ }^{3}$ Optamos por não trabalhar com o núcleo de desenvolvimento infantil da UFSC, pois privilegiamos neste estudo as análises referentes à Educação Básica.

${ }^{4}$ Fonte: ESEBA/UFU (2007).

${ }^{5}$ Nos momentos em que expusemos as respostas dos diretores, utilizamos a abreviação "D." para nos referir a eles, numerando-os de 1 a 10.

${ }^{6}$ Os tipos de deficiência assinalados pelos diretores como "outros" foram: paralisia cerebral, transtorno de atenção, transtorno bipolar e Síndrome de Down.

${ }^{7}$ Este termo refere-se a uma série de prescrições elaboradas a partir do Consenso de Washington, que ocorreu em meados dos anos 1980, quando os países do primeiro mundo definiram o futuro da economia mundial, as políticas de desenvolvimento e, especificamente, o papel do Estado (VIDAL, 2006).
} 
Régis Henrique dos R. Silva - Thiago V. Santiago

${ }^{8}$ Esta complementação salarial são os chamados "bônus salarial", que no caso do Estado de São Paulo são pagos aos professores, conforme os resultados das escolas em que trabalham nas provas do SARESP. O problema deste tipo de política de "valorização do professor", além da quebra de isonomia e a lógica de competitividade que passa a imperar entre as escolas e os professores, são as estratégias utilizadas nos dias das provas para melhorar os resultados destas, principalmente dos alunos com deficiência.

\section{Correspondência}

Régis H. dos Reis Silva - Rua Jasmim, n. 310, Apto. 43, Bl. A, Chácara Primavera, Campinas/ SP, CEP: $13087-460$.

E-mail: regishsilva@bol.com.br; thiago_shelter@hotmail.com

Recebido em 04 de março de 2010

Aprovado em 11 de maio de 2010 